
РЕАКТИВНЫХ И АДАПТИВНЫХ ПРЕОБРАЗОВАНИЙ БОЛЬШОГО САЛЬНИКА ПРИ ОПУХОЛЕВОМ ПОРАЖЕНИИ ЯИЧНИКОВ

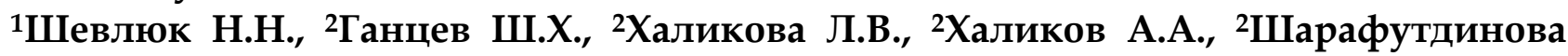
Л.А., ${ }^{2}$ Ишмуратова К.P.

1Оренбургский государственный медицинский университет, Оренбург; ${ }^{2}$ Башкирский государственный медицинский университет, Уфа, Россия, e-mail: k_histology@orgma.ru

\title{
ULTRASTRUCTURAL AND IMMUNOHISTOCHEMICAL STUDIES OF REACTIVE AND ADAPTIVE TRANSFORMATIONS OF THE GREATER OMENTUM AT TUMOR LESIONS OF THE OVARIES \\ ${ }^{1}$ Shevlyuk NN, ${ }^{2}$ Gantsev ShKh, ${ }^{2}$ Khalikova LV, ${ }^{2}$ Khalikov AA, ${ }^{2}$ Sharafutdinova LA, 2Ishmuratova KR \\ 1Orenburg State Medical University, Orenburg; ${ }^{2 B a s h k i r}$ State Medical University, Ufa, Russia, \\ e-mail: k_histology@orgma.ru
}

Дия циитирования:

Шевлюк Н.Н., Ганцев Ш.Х., Халикова Л.В., Халиков А.А., Шарафутдинова Л.А., Иимуратова К.Р. Ультраструктурные и иммуногистохимические исследования реактивных и адаптивных преобразований большого сальника при опухолевом поражении яичников// Морфологические ведомости.- 2020.- Том 28.- № 4.- С. 46-54. https://doi.org/10.20340/mvmn.2020.28(4):540

For the citation:

Shevlyuk NN, Gantsev ShKh, Khalikova LV, Khalikov AA, Sharafutdinova LA, Ishmuratova KR. Ultrastructural and immunohistochemical studies of reactive and adaptive transformations of the greater omentum in ovarian cancer. Morfologicheskie Vedomosti - Morphological Newsletter. 2020;28(4):46-54. https://doi.org/10.20340/mv-mn.2020.28(4):540

Резюме. Большой сальник является органом, в котором часто образуются метастазы злокачественных новообразований органов женской половой системы. Вопросы адаптивных и реактивных преобразований большого сальника в условиях опухолевого процесса в органах женской репродуктивной системы изучены недостаточно. Целью исследования явилось выяснение морфофункциональных ультраструктурных и иммуногистохимических изменений большого сальника у женщин с опухолевым поражением яичников. С использованием методов световой и электронной микроскопии, иммуногистохимии и морфометрии исследованы яичники 48 женщин, у которых диагностировали низкодифференцированную серознопапиллярную аденокарциному II стадии (20 пациенток, 1-я группа), III стадии (28 пациенток, 2-я группа). У пациенток с III стадией в большом сальнике выявлялись многочисленные метастазы опухоли. Результаты исследования показали, что у пациенток 2-й группы в около-опухолевых участках большого сальника сосуды микроциркуляторного русла были расширены, в соединительной ткани наблюдался умеренный отек, лейкоцитарная инфильтрация. Иммуногистохимические маркеры показали в опухоли и в около-опухолевых участках возрастание числа иммунокомпетентных клеток, преимущественно Т-лимфоцитов. В опухоли и в окружающих ее участках большого сальника отмечался процесс новообразования кровеносных капилляров, выявлены различия в плотности расположения коллагеновых фибрилл в разных участках серозной оболочки и показано наличие многочисленных отверстий, размеры которых уменьшены в участках с метастазами. Полученные результаты показывают адаптивные и репаративные возможности структур большого сальника при опухолевом процессе в органах женской репродуктивной системы, указывают на важную роль большого сальника в обеспечении защитных реакций в брюшной полости. В ответ на инвазию опухолевых клеток в большом сальнике активизируются процессы ангиогенеза, неолимфогенеза возрастает численность иммунокомпетентных клеток. Материалы исследования свидетельствуют о значительной пластичности и реактивности большого сальника в условиях опухолевого процесса в организме. Однако, наличие выраженной пролиферативной активности опухолевых клеток в метастазах опухоли указывает на то, что этих адаптивных возможностей недостаточно для противостояния инвазии опухоли в большой сальник. морфометрия

Ключевые слова: большой сальник, брюшина, опухоль яичника, ультраструктура, иммуногистохимия,

Summary. The greater omentum is an organ in which metastases of malignant neoplasms of the female reproductive system are often formed. The issues of adaptive and reactive transformations of the greater omentum under conditions of a tumor process in the organs of the female reproductive system have been insufficiently studied. The aim of the study was to elucidate morphological and functional ultrastructural and immune-histochemical changes in the greater omentum in women with ovarian tumor lesions. Using the methods of light and electron microscopy, immunohistochemistry and morphometry, the ovaries of 48 women were examined, who were diagnosed with poorly differentiated serous-papillary adenocarcinoma stage II (20 patients, group 1), stage III (28 patients, group 2). In stage III patients, numerous tumor metastases were detected in the greater omentum. The results of the study showed that in the patients of the 2nd group, in the peri-tumor areas of the greater omentum, the vessels of the microvasculature were dilated, in the connective tissue, moderate edema and leukocyte infiltration were observed. Immuno-histochemical markers showed 
an increase in the number of immunocompetent cells, mainly T-lymphocytes in the tumor and in the peri-tumor areas. In the tumor and in the surrounding areas of the greater omentum, the process of neoplasm of blood capillaries was noted, differences in the density of collagen fibrils in different parts of the serous membrane were revealed, and the presence of numerous holes was shown, the sizes of which were reduced in areas with metastases. The results obtained show the adaptive and reparative capabilities of the structures of the greater omentum during the tumor process in the organs of the female reproductive system, indicate the important role of the greater omentum in providing protective reactions in the abdominal cavity. In response to the invasion of tumor cells, the processes of angiogenesis are activated in the greater omentum, and the number of immunocompetent cells increases in neo-lymphogenesis. The materials of the study indicate a significant plasticity and reactivity of the greater omentum under conditions of a tumor process in the body. However, the presence of a pronounced proliferative activity of tumor cells in tumor metastases indicates that these adaptive capacities are insufficient to resist tumor invasion into the greater omentum.

Key words: greater omentum, peritoneum, ovarian tumor, ultrastructure, immunohistochemistry, morphometry

Введение. Большой сальник является одним из органов, в котором выявляются метастазы опухолей женской репродуктивной системы [1-7]. К настоящему времени опубликовано большое количество работ, касающихся различных фундаментальных и клинических аспектов злокачественных новообразований органов женской репродуктивной системы [1, 3, 6-12], выявлены основные механизмы опухолевой трансформации клеточных элементов яичника и их метастазирования в структуры большого сальника [3, 12-13], показаны пути метастазирования опухолей яичника в большой сальник [3, 12], выявлены основные закономерности и установлены иммуногистохимические маркеры ангиогенеза при метастазировании опухолей [14], установлен ряд иммуногистохимических маркеров клеточной адгезии, экспрессирующихся в опухолевых клетках при их метастазировании в большой сальник. Имеются работы, касающиеся вопросов иммунной защитной функции большого сальника [15-19]. В них показано, что лимфоидная ткань органа локализуется преимущественно в области так называемых «млечных пятен» [15-19]. Однако многие стороны реактивных и адаптивных морфофункциональных перестроек большого сальника при опухолевом процессе в яичниках, вопросы роли и значимости структур большого сальника в процессах развития опухолей яичников по-прежнему остаются недостаточно изученными и нуждаются в уточнении и дополнении $[3,7,12] . \mathrm{K}$ числу недостаточно исследованных вопросов относятся также вопросы адаптивных и репаративных возможностей незатронутых метастазами участков сальника [7].

Цель исследования: установление морфологических, включая ультраструктурные, и иммуногистохимических изменений большого сальника у женщин с опухолевым поражением яичников.

Материалы и методы исследования. Объектом исследования служили большие сальники 48 женщин, у которых была диагностирована низкодифференцированная серозно-папиллярная аденокарцинома высокой степени злокачественности II и III стадий. 20 пациенток имели опухоль яичников без метастазов в большом сальнике (II стадия). У 28 пациенток было выявлено метастатическое поражение большого сальника (III стадия). Возраст пациенток составлял от 50 до 65 лет. Для сравнения исследовали сальники 16 пациенток, которым была проведена экстирпация сальника во время операций по удалению доброкачественных опухолей яичника. Материал для морфологических исследований (биоптаты большого сальника) получали в Республиканском клиническом онкологическом диспансере, в отделении танатологии Бюро судебно-медицинской экспертизы Минздрава Республики Башкортостан, в центральном патологоанатомическом отделении Городской клинической больницы № 13 (Уфа, Россия). Исследовали поверхностные и внутренние участки большого сальника, при этом у пациенток с метастазами опухоли в большом сальнике исследовали участки, содержащие опухолевые узлы, около-опухолевые участки и участки, расположенные далеко от метастазов. Для светооптических исследований материал фиксировали в $12 \%$ нейтральном растворе формалина, обезвоживали в спиртах возрастающей крепости и заливали в парафин. Гистологические срезы толщиной 5-7 микрон окрашивали обзорными гистологическими (гематоксилином Майера и эозином) и иммуногистохимическими методами. Для электронно-микроскопического исследования использовали сканирующий растровый 
электронный микроскоп Tescan Vega-3SBH (Чехия) с вольфрамовым термокатодом. При подготовке к ультраструктурным исследованиям большого сальника производили деэпителизацию брюшины. Сушка поверхности образцов осуществлялась с помощью установки «FinecoatIonsputter JFC 1100» (JEOL, Япония). На этой же установке проводилось катодное напыление на исследуемую поверхность тонкого слоя золота.

В препаратах, окрашенных с помощью иммуногистохимических методов, выявляли экспрессию белков ki67, P53, CD34, CD44, CD7, CD4, CD8, D2-40. Иммуногистохимическое окрашивание проводили в соответствии со стандартными протоколами с применением следующих моноклональных антител: моноклональные мышиные антитела к ki67 anti-ki67 («DiagnosticBioSystems», США, клон MMIsameasMB67), в разведении 1:600; моноклональные мышиные антитела к человеческому протеину P53, клон DO-7, («DiagnosticBioSystems», США) в разведении 1:100; моноклональные мышиные антитела к человеческим эндотелиальным клеткам CD34, клон QBEND/10 («DiagnosticBioSystems», США), в разведении 1:50; моноклональные мышиные антитела к CD7, клон СВС.37 («DiagnosticBioSystems», США), в разведении 1:10; моноклональные мышиные антитела к трансмембранному гликопротеиду Т-хелперов/индукторов $\mathrm{CD} 4, \quad$ клон $1 \mathrm{f6}$ («DiagnosticBioSystems», США), в разведении 1:30; моноклональные мышиные антитела к человеческим Т-лимфоцитам CD8, клон 144B («DiagnosticBioSystems», CША), в разведении 1:50; моноклональные мышиные антитела к человеческому маркеру эндотелиоцитов D2-40, клон D2-40 (Dako, Дания) в разведении 1:100. При разведении антител использовали разбавитель Antibody Diluent («SPRING Bioscience», США). Использовалась система детекции - Reveal Polyvalent HRP - DAB Detection System («SPRING Bioscience», CШA). Окраска проводилась ручным и аппаратным способом с использованием гистостейнера Ventanaxt.

На условной единице площади окрашенных гематоксилином Майера и эозином гистологических срезов больших сальников проводили морфометрию структур большого сальника, учитывали количество сосудов микроциркуляторного русла и их размерные характеристики. На срезах, окрашенных иммуногистохимическими методами, проводили подсчет клеток, в которых выявлялась экспрессия соответствующих белков. С помощью критерия Шапиро-Уилка (Shapiro-Wilk's W-test) проводили анализ соответствия вида распределения количественных признаков закону нормального распределения. Сравнительный анализ групп проводился с помощью непараметрических методов (Uкритерий Манна-Уитни). Различия считали статистически значимыми при $\mathrm{p}<0,05$. Для выполнения работы было получено добровольное информированное согласие пациенток на участие в исследовании, а также положительное заключение локального этического комитета Оренбургского государственного медицинского университета (протокол заседания локального этического комитета № 237 от 16 октября 2019 года).

Результаты исследования и обсуждение. Результаты исследования показали, что у пациенток сальники, пораженные метастазами, имели меньшие размеры по сравнению с сальниками, не имеющими метастазов, при этом размеры большого сальника характеризовались выраженной индивидуальной изменчивостью, степень развития жировой ткани в органе также отличалось высокой индивидуальной вариабельностью. Жировая ткань располагалась преимущественно в виде долек различных размеров. Жировые дольки были отделены друг от друга прослойками рыхлой соединительной ткани. Клеточный состав междольковой соединительной ткани характеризуется преобладанием в ней клеток фибробластического дифферона (преимущественно малодифференцированные и дифференцированные фибробласты). Сосуды микроциркуляторного русла расположены как в прослойках междольковой соединительной ткани, так и внутри долек между адипоцитами. У большинства пациенток сальники после расправления имели четырехугольную форму, правая, средняя и левая части были хорошо выражены. Наличие метастазов отмечалось в разных участках сальника (рис. 1). При этом величина метастазов варьировала в широких пределах. Анализ препаратов показал, что у пациенток с метастатическим поражением большого сальника в тех участках, в которых 
отсутствуют метастазы опухоли, орган сохраняет свойственные ему общие принципы организации. При этом в нем возникает ряд адаптивных и реактивных изменений. При наличии метастазов в сальниках выявлены очаговые разрушения адипоцитов, обусловленные, прежде всего, нарушением микроциркуляции с образованием дефектов различных размеров, замещение подвергшейся деструкции жировой ткани соединительной тканью. Обращает на себя внимание особенность структуры сосудов микроциркуляторного русла, расположенных вблизи метастазов как в соединительной ткани серозной оболочки, так и внутри скоплений жировых клеток. Форма сосудов выглядит вариабельной (округлые, овальные, звездчатой формы), при этом большинство сосудов расширены. Диаметр большинства капилляров колебался в пределах от 5 до 25 мкм, тогда как капилляры в большом сальнике без метастазов имели менышие размеры (6 - 15 мкм). В около-опухолевых участках большого сальника наблюдаются явления неоангиогенеза, что согласуется с данными других авторов о выраженной экспрессии иммуногистохимического маркера ангиогенеза протеина CD34 в опухоли и около-опухолевых участках [20]. Толщина эндотелиальной выстилки неодинаковая, в пласте эндотелия выделяются клетки, высота которых значительно превышает высоту соседних клеток. Сходные по строению капилляры в около-опухолевых участках подслизистой основы желудка при раке желудка описаны в ряде работ [21-22].
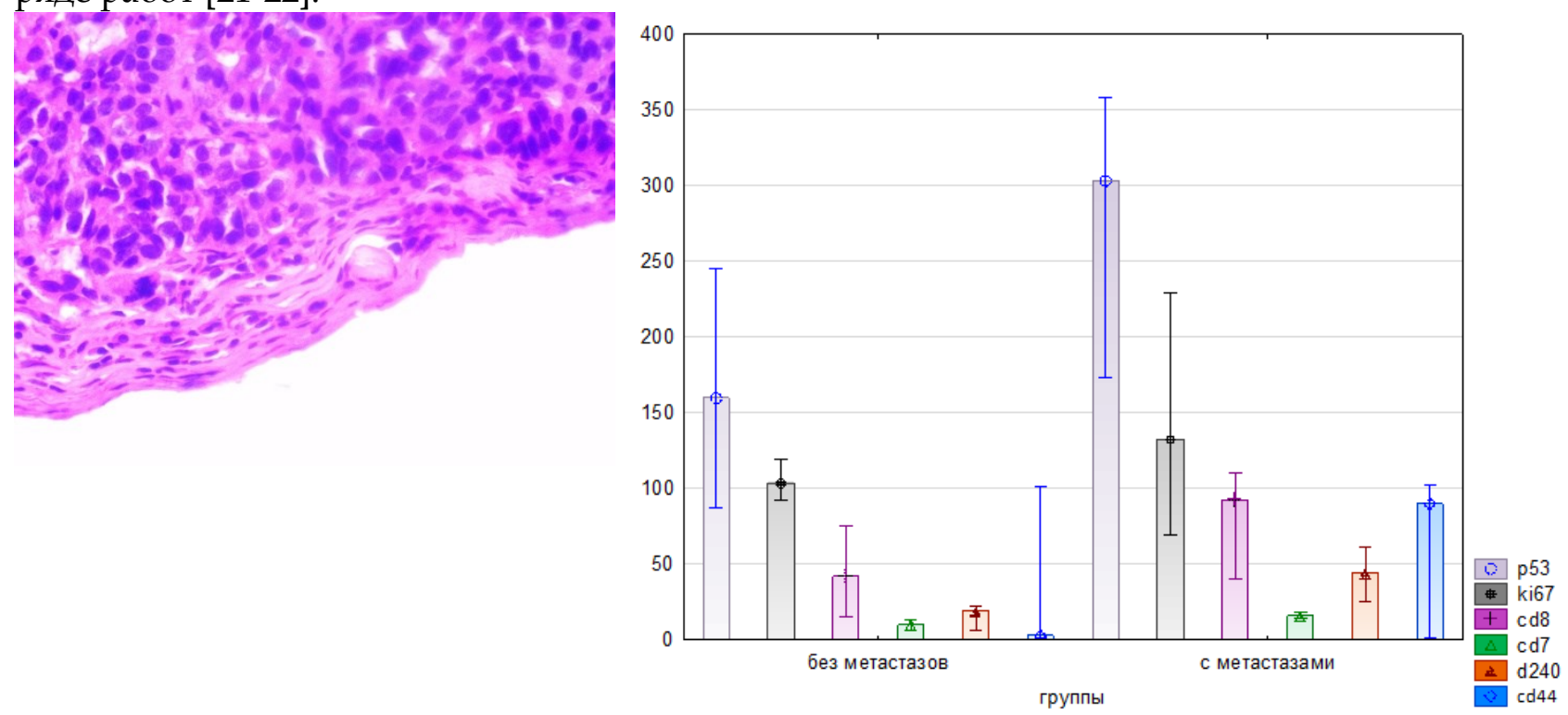

Рис. 1. Фрагмент большого Рис. 2. Среднее число ki67, P53, CD7- , CD-8, D240, сальника пациентки 54 лет с CD44 иммунопозитивных клеток в большом сальнике метастазами опухоли. Окр.: пациенток с метастазами опухоли и без метастазов гематоксилином Майера и опухоли в большом сальнике. эозином. Ув.: х400.

При сравнении участков большого сальника, пораженного метастазами и участков, где метастазы отсутствовали, была отмечена выраженная экспрессия маркера лимфатических эндотелиоцитов D2-40 (рис. 2). Это свидетельствует о процессах неолимфогенеза в исследуемых зонах. В эндотелии капилляров большого сальника без метастазов эндотелиальные клетки практически не различаются по форме. В капиллярах и венулах около-опухолевой зоны наблюдаются очаговые повреждения эндотелия, во многих капиллярах и венулах отмечен застой форменных элементов. Отмеченные явления обеспечивают возрастание миграции лейкоцитов из кровеносных сосудов. Вокруг многих сосудов микроциркуляторного русла отмечается очаговая, либо диффузная лейкоцитарная инфильтрация, среди лейкоцитов преобладали лимфоциты.

Анализ результатов иммуногистохимических реакций показал, что как в опухоли, так и вблизи ее выявляется большое количество клеток, экспрессирующих маркеры, 
Морфологические ведомости - Morphological Newsletter: 2020 Tом (Volume) 28 Bыnyск (Issue) 4

свойственные популяциям Т-лимфоцитов - CD7 и CD8 (рис. 3-4). В некоторых препаратах отмечалось наличие выраженного лейкоцитарного вала вокруг метастазов.

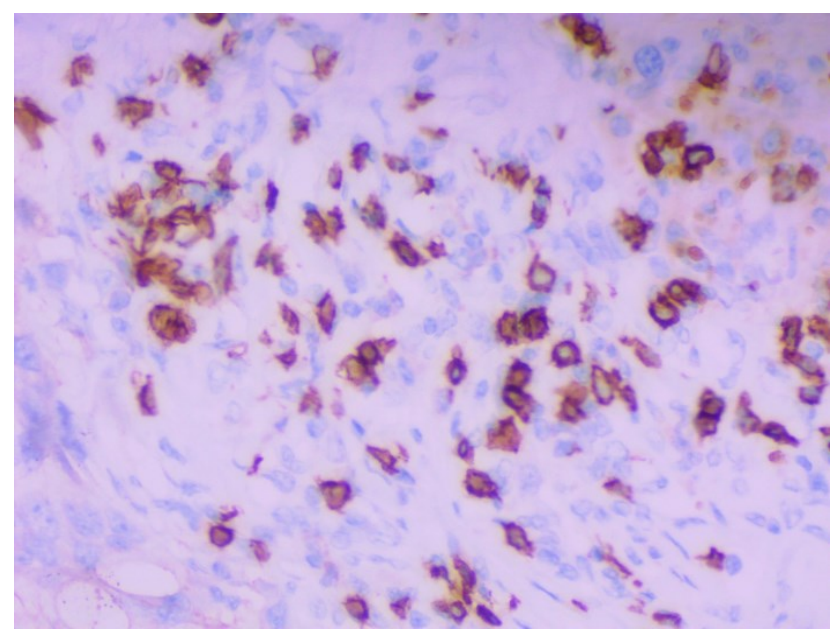

Рис. 3. Фрагмент большого сальника пациентки 58 лет с метастазами опухоли в большом сальнике. Иммуногистохимическое выявление экспрессии CD8. Ув.: х400.

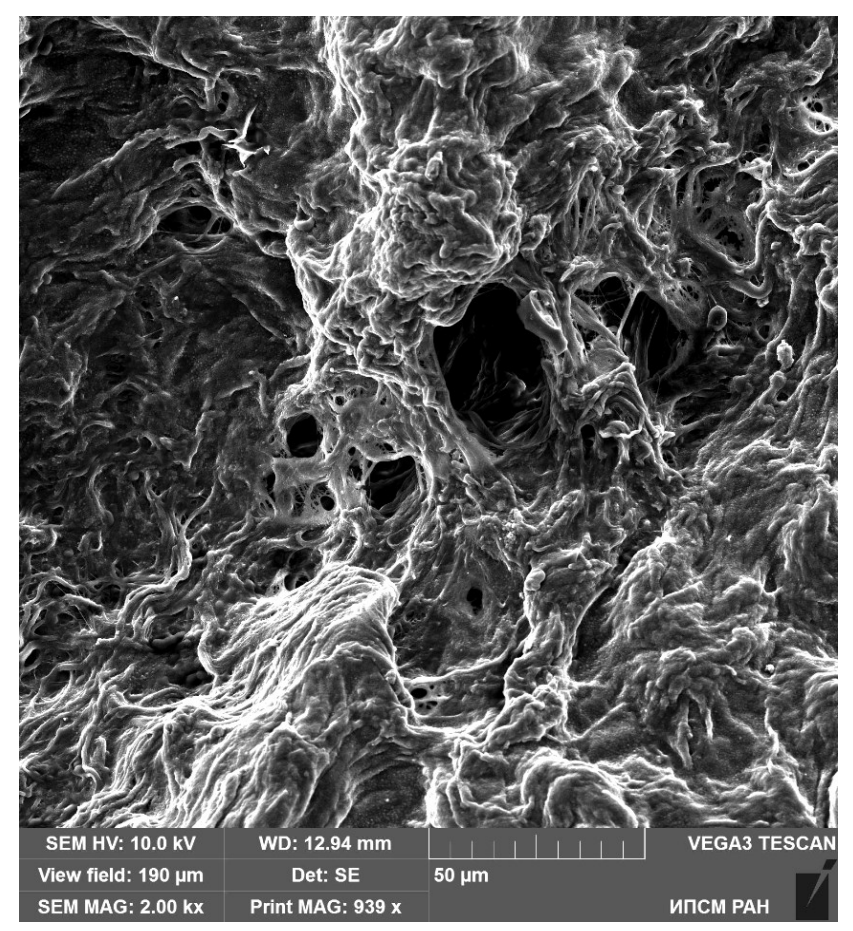

Рис. 5. Поверхность деэпителизированного участка серозной оболочки, не пораженного метастазами большого сальника пациентки 56 лет в области млечного пятна. Масштаб указан на рисунке.

Ультрамикрофотографии демонстрируют рыхлое расположение коллагеновых фибрилл и наличие отверстий разного размера в соединительной ткани серозной оболочки.

В ряде работ показано наличие так называемых «стомат» (пор) в поверхностном слое (мезотелии) серозной оболочки сальника, а также серозно-лимфатических насасывающих люков в серозных оболочках, обеспечивающих связь между перитонеальным пространством и лимфатическими капиллярами органов брюшной полости [23]. 


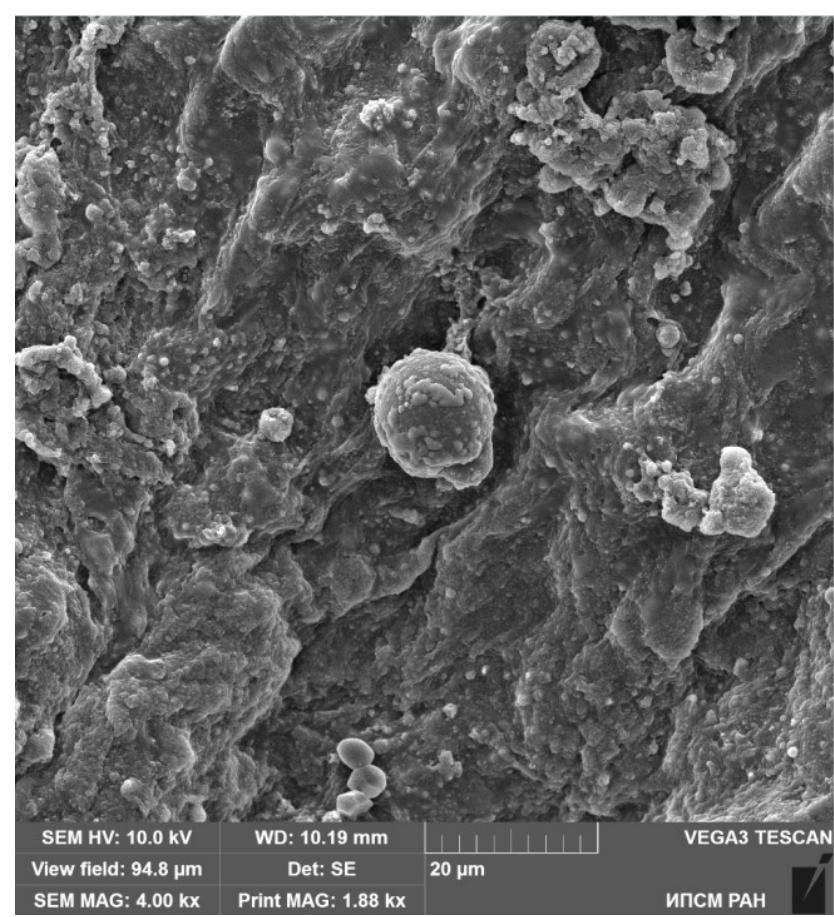

Рис. 7. Фрагмент деэпителизированной поверхности серозной оболочки большого сальника пациентки 58 лет с метастазами опухоли в большой сальник. Ультрамикрофото демонстрирует перемещение клетки через отверстие в серозной оболочке большого сальника. Масштаб указан на рисунке.

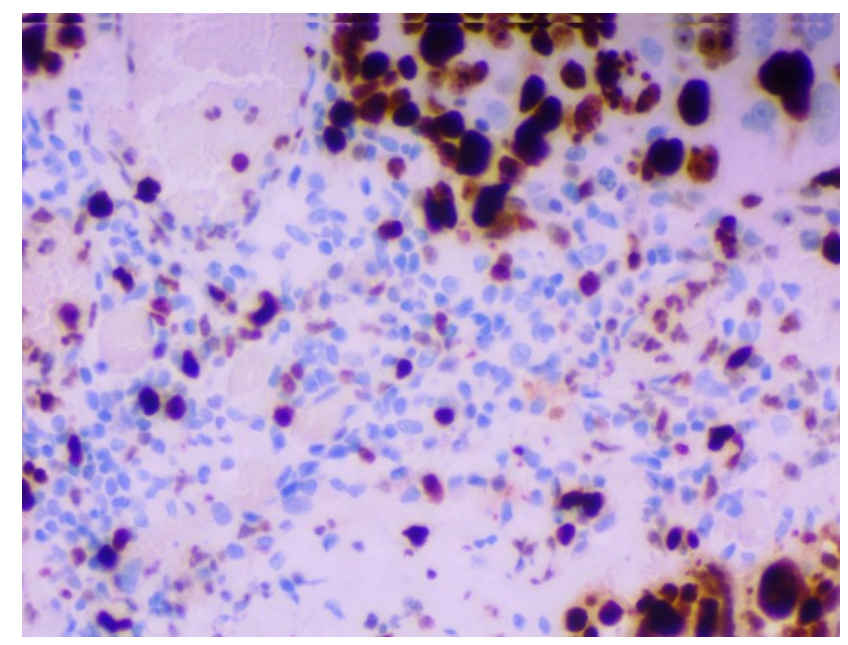

Рис. 9. Фрагмент большого сальника пациентки 58 лет с метастазами опухоли в большом сальнике. Иммуногистохимическое выявление экспрессии белка ki67. Увеличение: $x 400$.

Проведенный ультраструктурный анализ показал, что основу плотной соединительной ткани серозной оболочки большого сальника в области «млечного пятна» составляют коллагеновые фибриллы. Пучки коллагеновых фибрилл существенно различаются по толщине и ориентированы в различных направлениях. При этом плотность распределения пучков вариабельна в разных участках сальника. В серозной оболочке

Рис. 8. Фрагмент деэпителизированной поверхности серозной оболочки большого сальника пациентки 56 лет с метастазами опухоли в большом сальнике. Ультрамикрофото демонстрирует плотное расположение пучков коллагеновых волокон в соединительной ткани серозной оболочки. Масштаб указан на рисунке.

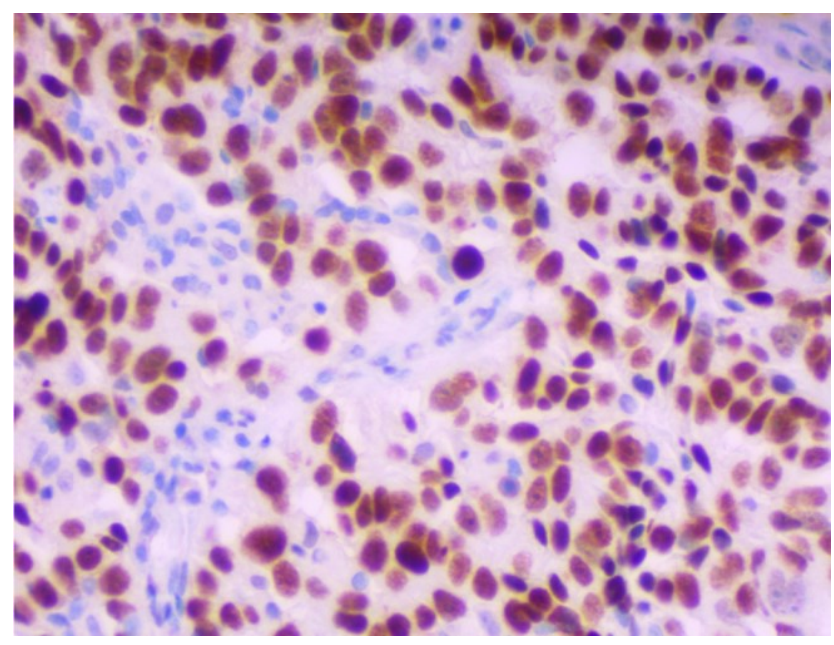

Рис. 10. Фрагмент большого сальника пациентки 58 лет с метастазами опухоли в большом сальнике. Иммуногистохимическое выявление экспрессии белка Р53.

Увеличение: $x 400$.

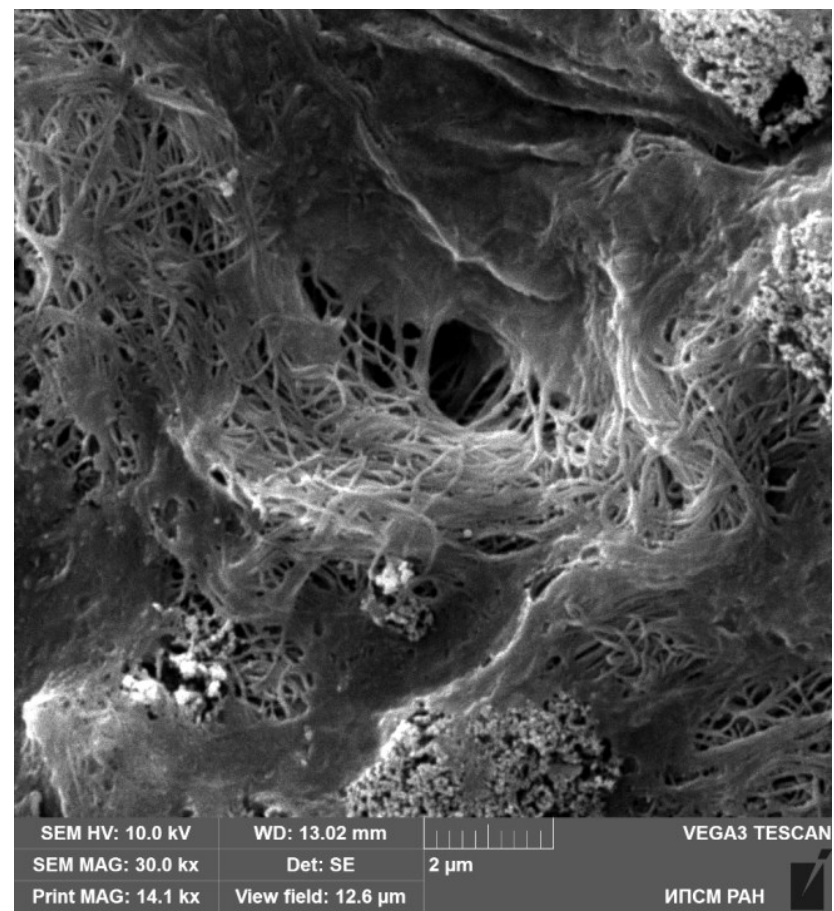


имеются участки, в которых соединительнотканная основа истончена, в этих участках наблюдаются отверстия, которые способствуют обмену жидкости между сальником и перитонеальным пространством. Наибольшее число таких отверстий выявляется в области так называемых «млечных пятен» сальника, которые ассоциируются с лимфоидной тканью. Из литературы известно, что величина отверстий в листках брюшины существенно различается, а также, что наибольшие по размеру отверстия содержатся в серозной оболочке, покрывающей диафрагму $[12,23]$. Согласно нашим данным, в серозной оболочке большого сальника размеры этих отверстий варьируют в пределах от 2,5 мкм до 25 мкм. Более рыхлое расположение коллагеновых фибрилл и наличие отверстий разного размера в соединительной ткани серозной оболочки определялось в сальнике, не пораженном метастазами, тогда как в сальнике с метастазами расположение коллагеновых волокон было более плотным (рис. 5-8). Поскольку эти отверстия представляют собой промежутки между пучками коллагеновых волокон, очевидно, что они являются непостоянными образованиями и могут формироваться в любых участках серозной оболочки. Различия в диаметре этих отверстий, по-видимому, обусловлены объемом и скоростью транспорта жидкости и клеток через них, то есть со степенью их функциональной активности. Различный диаметр отверстий, также, вероятно, является отражением разных по времени стадий формирования и закрытия этих структур. Нами не было выявлено закономерностей в распределении этих отверстий между участками сальника без метастазов и околоопухолевыми участками. Анализ электронограмм показал, что эти отверстия позволяют перемещаться из сальника в перитонеальное пространство и обратно не только жидкости, но также и различным клеткам как иммуноцитам, так и опухолевым клеткам. Рисунок 4 демонстрирует проходящую через отверстие в серозной оболочке клетку. Расположение фибриллярных структур в непораженных метастазами участках сальника было более рыхлым по сравнению с участками с метастазами и около-опухолевыми участками (рис. 58). В связи с этим, формирование отверстий между коллагеновыми пучками в условиях метастатического поражения происходит хуже, это может приводить к нарушению перемещений клеточных элементов иммунной системы в этих участках серозной оболочки. Более плотное расположение коллагеновых фибрилл в участках с наличием метастазов может также являться одной из причин большей адгезии опухолевых клеток в эти участки, подтверждаемое большим количеством клеток с экспрессией одного из маркеров клеточной адгезии CD44.

Анализ экспрессии белка CD44 показал, что выраженная экспрессия этого протеина выявляется в болышинстве клеток опухоли и не выявляется в клеточных элементах сальника, в котором отсутствуют метастазы. Одновременно с выраженной экспрессией CD44 в большинстве клеток опухоли обнаруживается экспрессия белков ki67 и Р53 (рис. 2, рис. 9-10). Как показал статистический анализ, выраженность экспрессии белка Р53 была более значительной, чем экспрессия белка ki67 (рис. 2). Сопоставление результатов, отмеченных выше иммуногистохимических реакций на выявление протеинов (наличие большого числа клеток, экспрессирующих Р53 на фоне множества клеток, экспрессирующих ki67, рис. 2) указывает на наличие нарушений регуляторных механизмов программированной клеточной гибели, что отражается и на процессах пролиферации опухолевых клеток. В своей совокупности полученные результаты по экспрессии CD44, ki67 и P53 в клетках метастазов опухоли подтверждают представление о высокой злокачественности низкодифференцированной серозно-папиллярной аденокарциномы яичника.

В ряде работ показано значительное развитие лимфоидной ткани в большом сальнике и обоснована важная роль структур большого сальника в обеспечении иммунных защитных реакций организма [15-19, 24]. Анализ результатов нашего исследования подтверждает наличие значительного числа иммунокомпетентных клеток, преимущественно клеточных элементов, ответственных за клеточный иммунитет, в составе структур большого сальника в области метастазов и в около-опухолевой области, в том числе в составе серозной оболочки органа и на ее поверхности. На это указывает наличие в 
Морфологические ведомости - Morphological Newsletter: 2020 Tом (Volume) 28 Bыnуск (Issue) 4

стенке большого сальника значительного числа клеточных элементов с выраженной экспрессией белков CD7 и CD8 (рис. 2-4).

Заключение. Полученные в настоящем исследовании результаты показывают адаптивные и репаративные возможности структур большого сальника при опухолевом процессе в органах женской репродуктивной системы, указывают на важную роль большого сальника в обеспечении защитных реакций в брюшной полости. В ответ на инвазию опухолевых клеток в большом сальнике активизируются процессы ангиогенеза, неолимфогенеза возрастает численность иммунокомпетентных клеток. Материалы исследования свидетельствуют о значительной пластичности и реактивности большого сальника в условиях опухолевого процесса в организме. Однако, наличие выраженной пролиферативной активности опухолевых клеток в метастазах опухоли указывает на то, что этих адаптивных возможностей недостаточно для противостояния инвазии опухоли в большой сальник.

Авторы заявляют об отсутствии каких-либо конфликтов интересов при планировании, выполнении, финансировании и использовании результатов настоящего исследования.

\section{Литература \\ References}

1. Seidman JD, Kurman RJ. Pathology of ovarian carcinoma. Hematol. Oncol. Clin. North Am. 2003;17(4):909 - 925.

2. Schoppmann SF. Limphangiogenesis, inflammation and metastasis. Anticancer Res. 2005;25:4503-4511.

3. Khalikova LV. Bol'shoj sal'nik: morfofunkcional'nye osobennosti i klinicheskoe znachenie $v$ onkologii. Kreationaja hirurgija i onkologija. 2011;4:131-134.

4. Prat J. Ovarian carcinomas: five distinct diseases with different origins, genetic alterations, and clinicopathological features. Virchows Archiv. 2012;460(3):237-249.

5. Kurman RJ, Shih IM. The dualistic model of ovarian carcinogenesis: revisited, revised and expanded. Am. J. Pathol. 2016;186(4):733-747.

6. Votincev AA, Banin VV, Solov'jov GS, Shidin VA. Receptornyj status opuholevyh kletok $i$ mehanizmy narushenija tkanevogo gomeostaza pri kancerogenezeseroznogoovarial'nogoraka. Zhurnal anatomii $i$ gistopatologii. 2019;8(2):22-29.

7. Shevljuk NN, Khalikova LV, Khalikov AA. Morfofunkcional'naja harakteristika bol'shogo sal'nika. Zhurnal anatomii i gistopatologii. 2020;9(2):90-99.

8. Erturk E, Tuncel E. Polycystic ovarian disease and serum leptin levels. Fertility and Sterility. 2003;80:1068-1069.

9. Moore RG, Maclaughlan S. Current clinical use of biomarkers for epithelial ovarian cancer. Current opinion in oncology. 2010;22:492-497.

10. Ino K. Indoleamine 2,3 - dioxygenase and immune tolerance in ovarian cancer. Current Opinion in Obstetrics and Cynicology. 2011;23:13-18.

11. Longuespee R, Boyon C, Desmons A, Vinatier D, Leblans E, Farre I, Wisztorski M, Ly K, D'Anjou F, Day R, Fournier I, Salzet M. Ovarian cancer molecular pathology. Cancer and metastasis review. 2012;31(3-4):713-732.

12. Gancev ShH, Solomennyj SV, Gancev KSh, Kzyrgalin ShR, Minigazimov RS, Loginova MV Ocenka sostojanija serozno-limfaticheskih ljukov pri peritoneal'nom kanceromatoze po dannym skaniruj ushhejj elektronnojmikroskopii (naprimer edia fragmal'noj brjushiny). Kreationaja hirurgijai onkologija. 2014;4:4-10.

13. Kenny HA, Kaur S, Coussens LM, Lengyel E. The initial steps of ovarian cancer cell metastasis are mediated by MMP-2 cleavage of vitronectin and fibronectin. Journal of clinical investigation. 2008;118:1367-1379.

14. Nishida N, Yano H, Komai K, Nishida T, Kamura T, Kojiro M. Vascular endothelial growth factor C and vascular endothelial growth factor receptor 2 are related closely to the prognosis of patients with ovarian carcinoma. Cancer. 2004;101:1364-1374. 
Морфологические ведомости - Morphological Newsletter: 2020 Tом (Volume) 28 Bыnуск (Issue) 4

15. Berezovskaja SJe, Markov II, Funkcional'noe znachenie bol'shogo sal'nika kakim munokompetentnogo organa. V sb. Fiziologija vegetativnoj nervnoj sistemy. Vyp. 5. Kujbyshev: KMI; 1988:17-18.

16. Makurina ON. Zakonomernosti morfofunkcional'noj organizacii bol'shogo sal'nika mlekopitajushhih. Avtoref. diss. dokt. biol. nauk. Saransk, 2001.- 37s.

17. Markov II, Gusarov AA, Shalaev SV, Drogobych OV. Morfofunkcional'nye izmenenija vperifericheskih organah immunnoj sistemy laboratornyh zhivotnyh pri vakcinacii $i$ hzhivoj grippoznoj vakcinoj. Morfologicheskie vedomosti. 2005;3-4:64-66.

18. Markov II, Ljubaeva EV, Shalaev SV, Sopova IL. Osobennosti strukturnoj organizacii mikrososudistogo rusla bol'shogo sal'nika laboratornyh zhivotnyh. Morfologicheskie vedomosti. 2007;3-4:45-48.

19. Miura M, Yonemura Y. Morphological study of human omental milky spots and their morphological changes in omental disseminated metastasis. Jap. J. Lymphology. 2011;34:2-6.

20. Nefedova NA, Harlova OA, Danilova NV, Mal'kov PG, Gajfullin NM. Markery angiogeneza pri opuholevom roste. Arhivpatologii. 2016;2:55-62.

21. Stadnikov AA, Sen'chukova MA, Shevljuk NN, Bokov DA. Morfologicheskaja harakteristika sosudov pod slizistoj osnovy zheludka na uchastkah, prilezhashhih k opuholi. Morfologija. 2011;140(4):18-24.

22. Senchukova M, Kiselevsky MV. The «cavitary» type of angiogenesis by gastric cancer. Morphological characteristics and prognostic value. J. Cancer. 2014;5(5):311-319.

23. Karaganov JaL, Mironov VA, Gusev SA. O fiziologicheskom znachenii i mehanizmah obrazovanija «stomat» $v$ mezoteliibrjushiny. Arhiv anat. 1981;80(4):85-94.

24. Krist LFG., Eestermans IL, Steenbergen JJE, Hoefsmit ECM, Cuesta MA, Meyer S, Beelen RH. Cellular composition of milky spots in the human greater omentum: an immunochemical and ultrastructural study. Anatomical Record. 1995;241:163-174.

\section{Авторская справка}

Шевлюк Николай Николаевич, доктор биологических наук, профессор, заслуженный работник высшей школы РФ, профессор кафедры гистологии, цитологии и эмбриологии, Оренбургский государственный медицинский университет, Оренбург, Россия; e-mail: k_histology@orgma.ru

Ганцев Шамиль Ханафиевич, доктор медицинских наук, профессор, действительный член (академик) Академии наук Республики Башкортостан, заведующий кафедрой онкологии с курсами онкологии и патологической анатомии, Институт дополнительного профессионального образования, Башкирский государственный медицинский университет, Уфа, Россия, e-mail: prfg@mail.ru

Халикова Лариса Вячеславовна, ассистент кафедры гистологии, цитологии и эмбриологии, Башкирский государственный медицинский университет, Уфа, Россия; e-mail: anifas09@mail.ru

Халиков Айрат Анварович, доктор медицинских наук, профессор, заведующий кафедрой судебной медицины, Башкирский государственный медицинский университет, Уфа, Россия; e-mail: airatexpert@mail.ru

Шарафутдинова Люция Ахтямовна, кандидат биологических наук, доцент кафедры гистологии, цитологии и эмбриологии, Башкирский государственный медицинский университет, Уфа, Россия; e-mail: sharafla@yandex.ru

Ишмуратова Камилла Рафхатовна, аспирант кафедры онкологии с курсами онкологии и патологической анатомии, Институт дополнительного профессионального образования Башкирский государственный медицинский университет, Уфа, Россия, e-mail: kamilla93@bk.ru 